\title{
Multiple Visceral Resections for Synchronous Left and Transverse Colon Adenocarcinoma with Gastrocolic-cutaneous Fistula - Case Report and Literature Review
}

\author{
NICOLAE BACALBASA ${ }^{1}$, CLAUDIA STOICA ${ }^{2}$ and IRINA BALESCU ${ }^{3}$ \\ ${ }^{1}$ Department of Obstetrics and Gynecology, \\ Carol Davila University of Medicine and Pharmacy, Bucharest, Romania; \\ ${ }^{2}$ Department of General Surgery, Ilfov County Hospital, Bucharest, Romania; \\ ${ }^{3}$ Department of General Surgery, Ponderas Academic Hospital, Bucharest, Romania
}

\begin{abstract}
Synchronous adenocarcinomas of the colon represent a rare situation, characterized by the presence of at least two colonic malignancies separated by at least $4-\mathrm{cm}$ distance, in the absence of submucosal spread. Gastrocoliccutaneous fistulas also represent a rare complication associated with the presence of colonic or gastric adenocarcinomas. We present the case of a 61-year-old patient who presented for abdominal pain, vomiting, weight loss and cutaneous exteriorization of purulent liquid. Intraoperatively, a large centro-abdominal tumor with gastroduodenal, pancreatic and colonic invasion was found in association with a synchronous left colonic tumor. The tumors were resected en bloc with distal gastrectomy, cephalic pancreatoduodenectomy, segmental enterectomy, subtotal colectomy and upper abdominal lymph node dissection. The histopathological studies revealed the presence of two synchronous colonic tumors: one located on the transverse colon, with pancreatic, duodeno-jejunal and gastric invasion and gastrocolic-cutaneous fistula, and a second one located on the left colon. Both tumors proved to be moderately differentiated colonic adenocarcinomas. At 1year follow-up the patient remains free of any recurrent disease.
\end{abstract}

Multiple colonic adenocarcinomas were first reported by Czemy et al. in 1880 and have a reported incidence of 2-8\% (1-3). According to the time of development, multiple colonic adenocarcinomas are classified as synchronous and

Correspondence to: Nicolae Bacalbașa, Dimitrie Racoviță Street, no. 2, Bucharest, Romania. Tel: +40 723540426, e-mail: nicolae_ bacalbasa@yahoo.ro

Key Words: Synchronous colonic adenocarcinoma, multiple visceral resections, gastrocolic cutaneous fistulas. metachronous. Synchronous colonic carcinomas usually involve the rectum and the colon and, according to Cunliffe et al.'s study, these tumors can coexist at the time of diagnosis or can be detected within a 6-month period postoperatively (1). The main histopathological feature which defines synchronous colonic malignancies is the presence of a distance of at least $4 \mathrm{~cm}$ between the two lesions, in the absence of submucosal spread which, when present, characterizes the metastatic origin of the distal tumor (4). Most often these synchronous lesions are seen in elderly patients, octogenarians being most frequently reported, and usually affect the rectum and sigmoidal colon $(1,5,6)$. In the context of a transverse colon adenocarcinoma, the development of a complex fistula has been explained through two theories: the first suggests a contiguous spread through the gastrocolic ligament of neoplastic cells from the colon to the gastric wall, while the second theory holds that a tumor ulceration arises which induces a peritoneal reaction; this phenomenon will create peritumoral adhesions and perforation in the adjacent organs (7). According to the involved viscera, these fistulas are classified as external if cutaneous involvement is present, or internal if other internal viscera are involved; furthermore, according to the number of involved viscera, fistula can be classified as simple or complex: complex (or complicated) fistula refers to the situation in which multiple visceral involvement is encountered $(8,9)$. Reported for the first time by Albrecht von Haller in 1755 in the context of a gastric tumor (10), gastrocolic fistulas usually occur in the context of gastric or transverse colonic cancer; other situations in which these fistulas might be encountered include inflammatory bowel disease, congenital disorders or iatrogenic origin, after percutaneous endoscopic gastrostomy tube migration (11).

We present the case of a patient with synchronous left and transverse colon adenocarcinoma with gastrocolic-cutaneous fistula, and review relevant literature. 


\section{Case Report}

A 61-year-old patient presented for abdominal pain, vomiting, weight loss and cutaneous exteriorization of purulent liquid (Figure 1). The preoperative studies revealed the presence of a gastrocolic-cutaneous fistula, probably secondary to the presence of a malignant process involving the large gastric curvature and the transverse colon. An upper digestive endoscopy was performed and revealed the presence of an infiltrated, tumoral area on the greater curvature, in association with the presence of a fistular orifice. The lower digestive endoscopy revealed the presence of a left colic tumor at $45 \mathrm{~cm}$ from the external anal orifice in association with a synchronous transverse colonic tumor with a central fistular orifice. The patient was submitted to surgery; a large centro-abdominal tumor with gastroduodenal, pancreatic and colonic invasion was found in association with a synchronous left colonic tumor. The tumors were resected en bloc with distal gastrectomy, cephalic pancreatoduodenectomy, segmental enterectomy, subtotal colectomy, parietal resection and upper abdominal lymph node dissection (Figures 2-8).

The macroscopic examination of the specimen revealed an $11 \times 7 \times 6 \mathrm{~cm}$ tumor with gastroduodenal and colonic invasion and a second tumor located at a distance of $5 \mathrm{~cm}$ from the first, measuring $3 \mathrm{~cm}$, which diminished the lumen of the left colon. The histopathological studies revealed the presence of two synchronous colonic tumors: one located on the transverse colon, with pancreatic, duodeno-jejunal and gastric invasion and gastrocoliccutaneous fistula, and the second located on the left colon, while the parietal wall and the adjacent area of the skin presented no signs of tumoral invasion. Both tumors proved to be moderately differentiated colonic adenocarcinomas. The microscopic analysis also revealed the presence of lymph node metastasis in one out of the 12 retrieved lymph nodes. In order to exclude the association of a gastric tumor, immunohistochemical studies were performed and revealed positivity for cytokeratin-20 (CK20), CK7 and caudal-type homeobox transcription factor (CDX2), supporting the diagnosis of colonic adenocarcinoma infiltrating the gastroduodenal wall.

Postoperatively, the patient developed a febrile syndrome with unknown origin; computed tomography performed on the seventh postoperative day excluded any intra-abdominal collection or abscess which might explain the origin of the febrile episode. A conservative antibiotic treatment was administered with good results, the patient being discharged on the 16th postoperative day. One month later, he underwent six cycles of adjuvant chemotherapy with 5-fluorouracil and folinic acid being administered. At 1-year follow-up the patient remains free of any recurrent disease.

\section{Discussion}

The true incidence of synchronous colorectal carcinoma is not well known due to the fact that in some cases, the second malignancy can easily be overlooked, hence the real incidence might by higher than that reported; however, most authors agree that the incidence ranges between 1.1 and $8.1 \%$, with higher rates in Europe and Asia, and a lower rate in America (12). Regarding the age at presentation, most authors report that it is usually higher for those with synchronous lesions when compared to those with solitary lesions $(1,5,6,12)$; however, there is no common consensus, other studies revealing similar ages for the two pathological entities (13). In regard to the association of predisposing conditions, it has been reported that synchronous colonic malignancies usually occur in patients presenting inflammatory bowel diseases such as ulcerative colitis, Crohn's disease or hyperplastic colonic polyposis (14-16). When it comes to the most frequent locations of synchronous colorectal tumors, most authors agree that the most commonly involved sites are the sigmoidal colon and rectum $(1,5,6,12)$; however, some authors demonstrated that the ascending colon is particularly interesting, probably due to the presence of certain genetic predisposing factors (12), while others reported that synchronous tumors usually occur in the same segment of the colon or close to each other $(13,17)$. However, the sine qua non condition for defining synchronous, independent colorectal tumors (i.e. not a primary tumor with a distant metastasis) is the presence of at least $4 \mathrm{~cm}$ between the two lesions, with no sign of submucosal invasion between the two lesions (4). According to this criterion, our case can be considered as a case of synchronous colonic adenocarcinoma, the distance between the two lesions being $5 \mathrm{~cm}$ in the absence of submucosal spread. The particularities of our case in regard to the presence of synchronous lesions were the absence of any predisposing condition (such as colonic polyposis or inflammatory bowel disease), the location of the lesions (involving the transverse colon and the left colon, and not the right, sigmoidal colon or rectum, as it has been reported as common location), as well as the relative young age at diagnosis.

Another particularity of the case was the presence of local invasion of the transverse colic tumor, necessitating multiple visceral resections in this area, as well as the presence of the complex gastrocolic-cutaneous fistula. The presence of local invasion of the transverse colonic tumor as well as the presence of the complex fistula required an aggressive surgical procedure consisting of subtotal colectomy en bloc with distal gastrectomy, pancreatoduodenectomy, segmental enterectomy and parietal wall resection in association with upper abdominal lymph node dissection. The necessity for extensive surgery has been widely demonstrated in patients presenting 


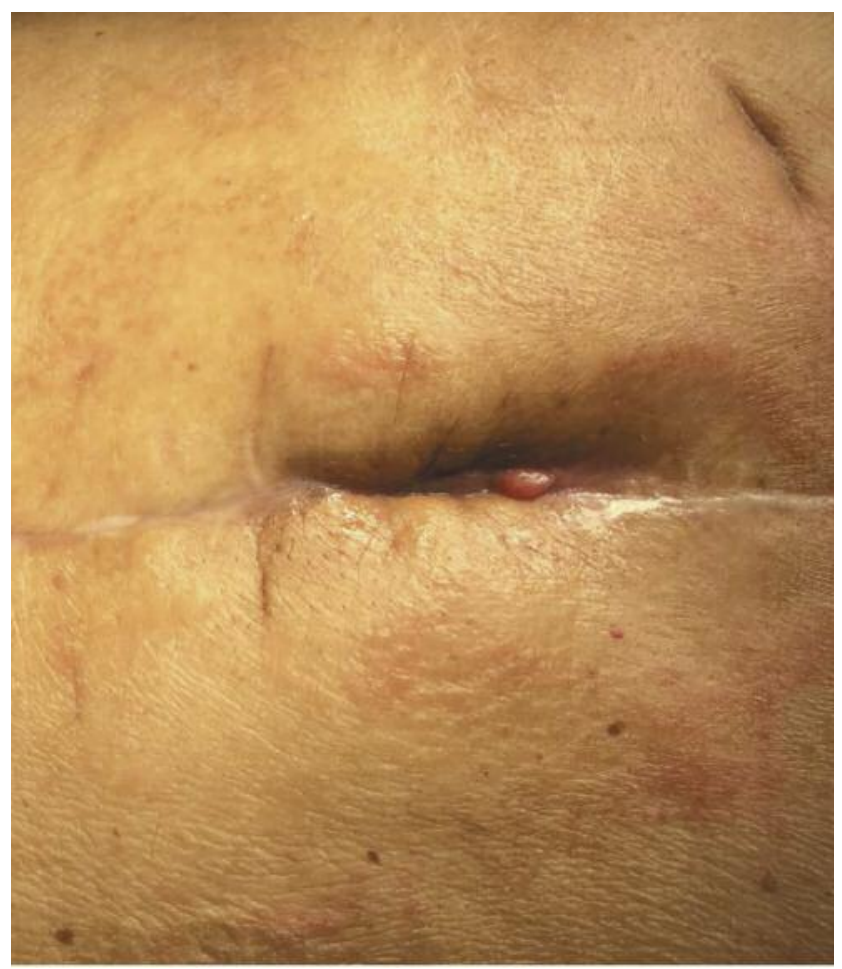

Figure 1. The orifice of the chronic cutaneous fistula.

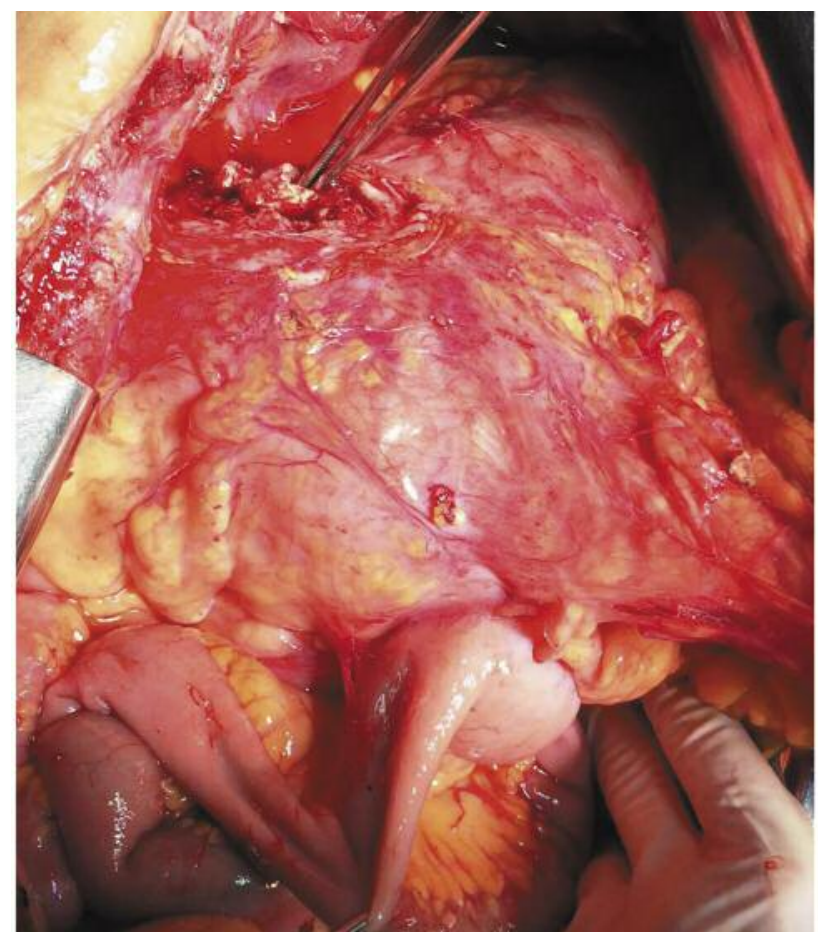

Figure 2. Initial intraoperative aspect: large upper abdominal mass invading the stomach, the duodenum, the transverse colon and the parietal wall.

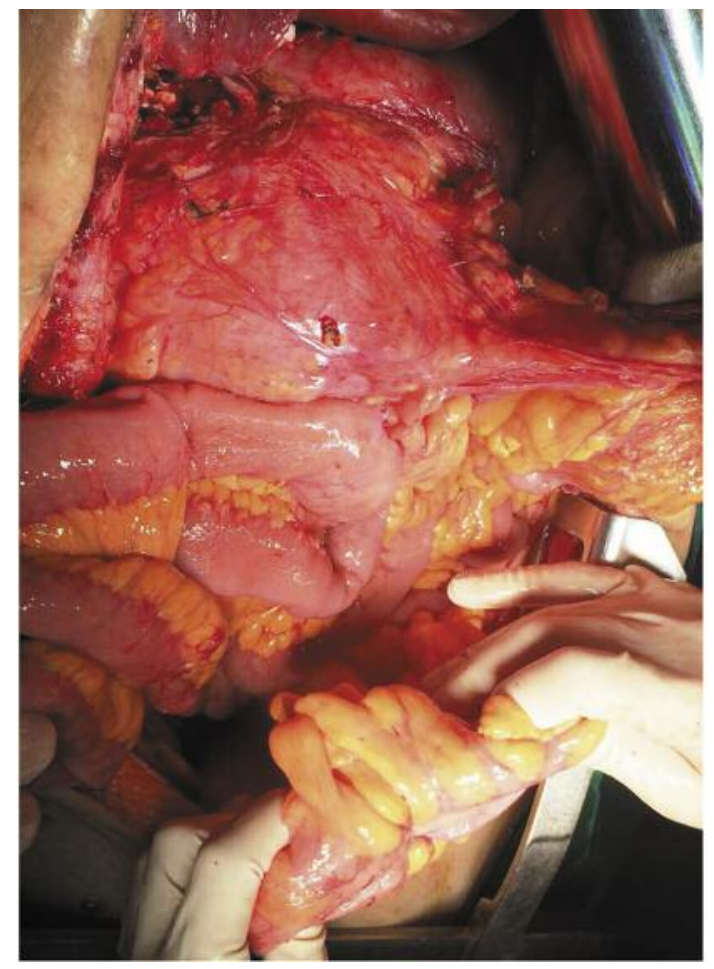

Figure 3. Initial intraoperative aspect: association of the second tumor on the left colon.

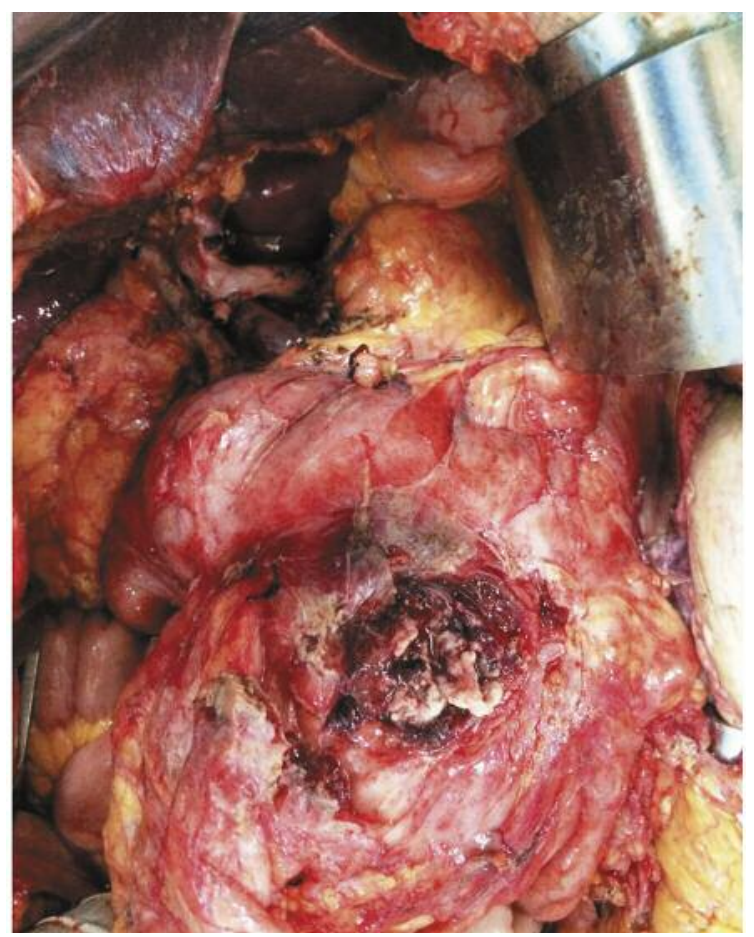

Figure 4. The aspect after en bloc mobilization of the tumor with distal gastrectomy, transverse colectomy, pancreatoduodenectomy and lymph node dissection. 


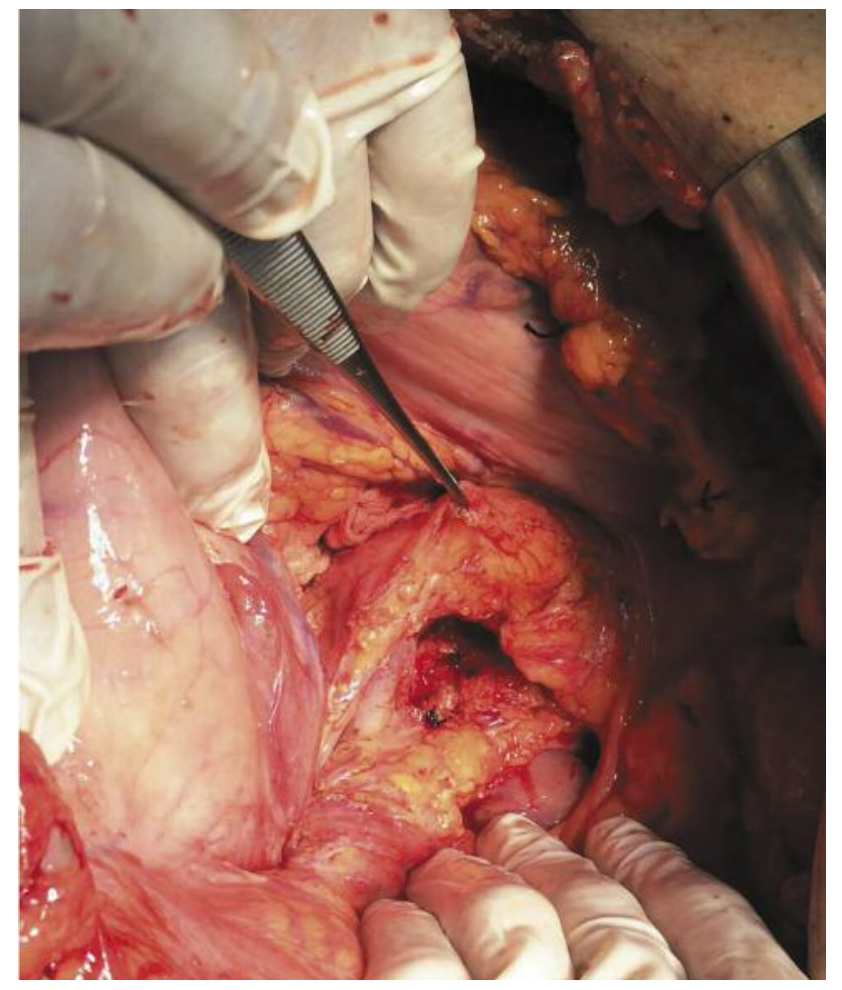

Figure 5. Preparing the pancreatic body for transection.

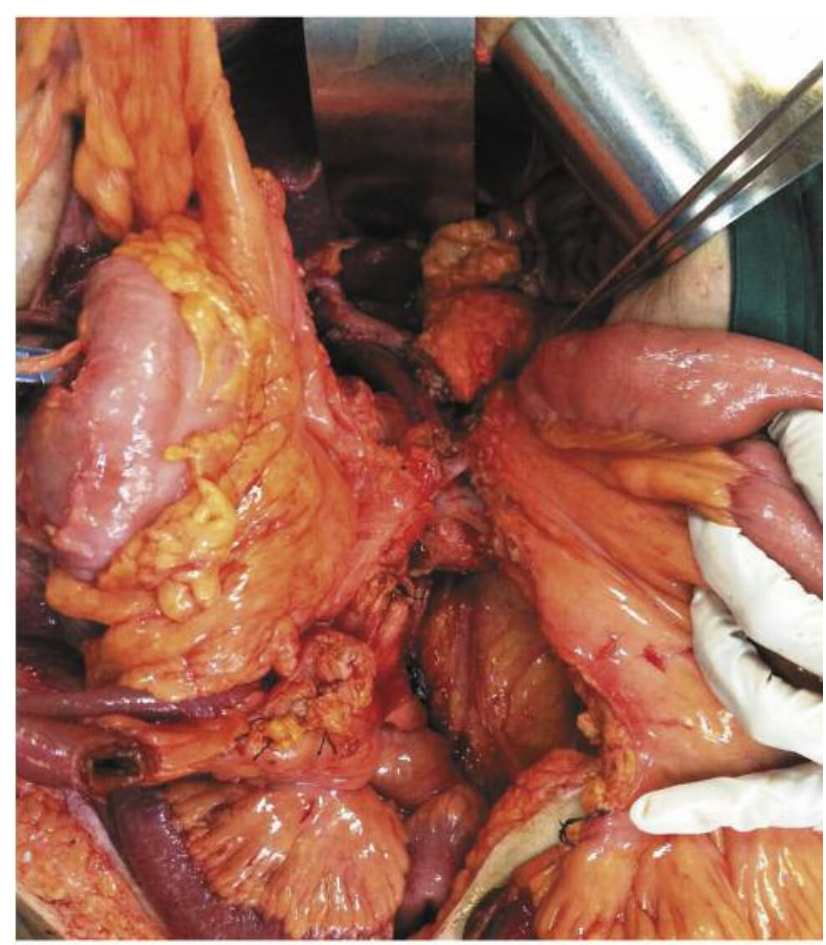

Figure 6. The general aspect after pancreatic transection.

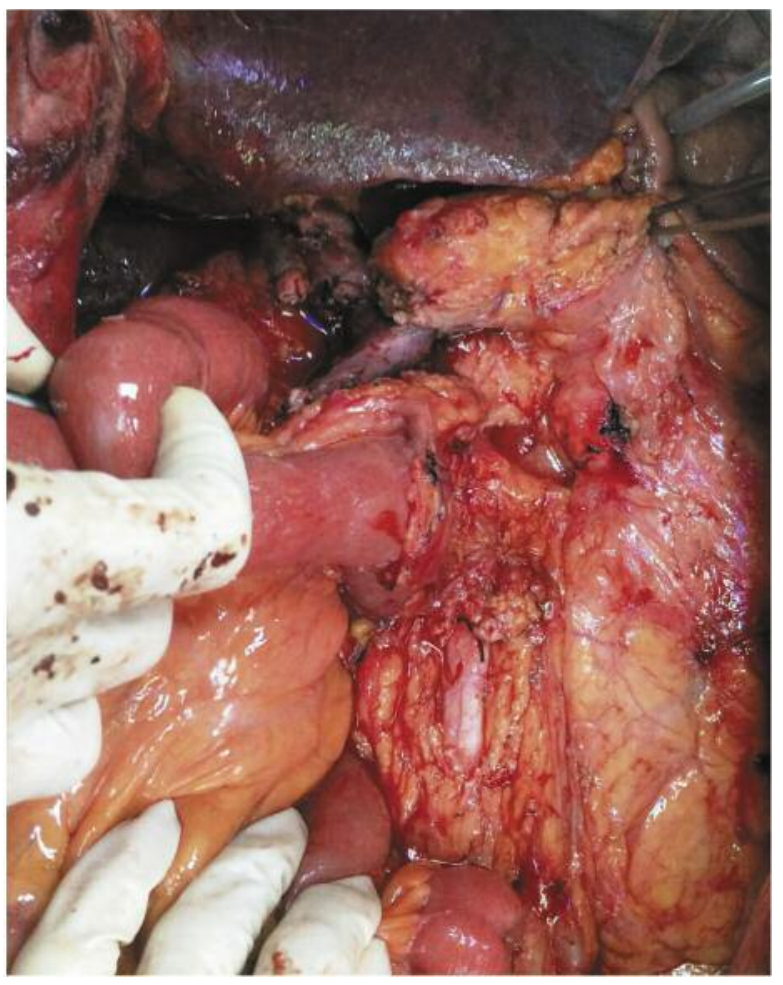

Figure 7. The final aspect after en bloc removal of the tumors with subtotal colectomy, distal gastrectomy, cephalic pancreatoduodenectomy and segmental enterectomy.

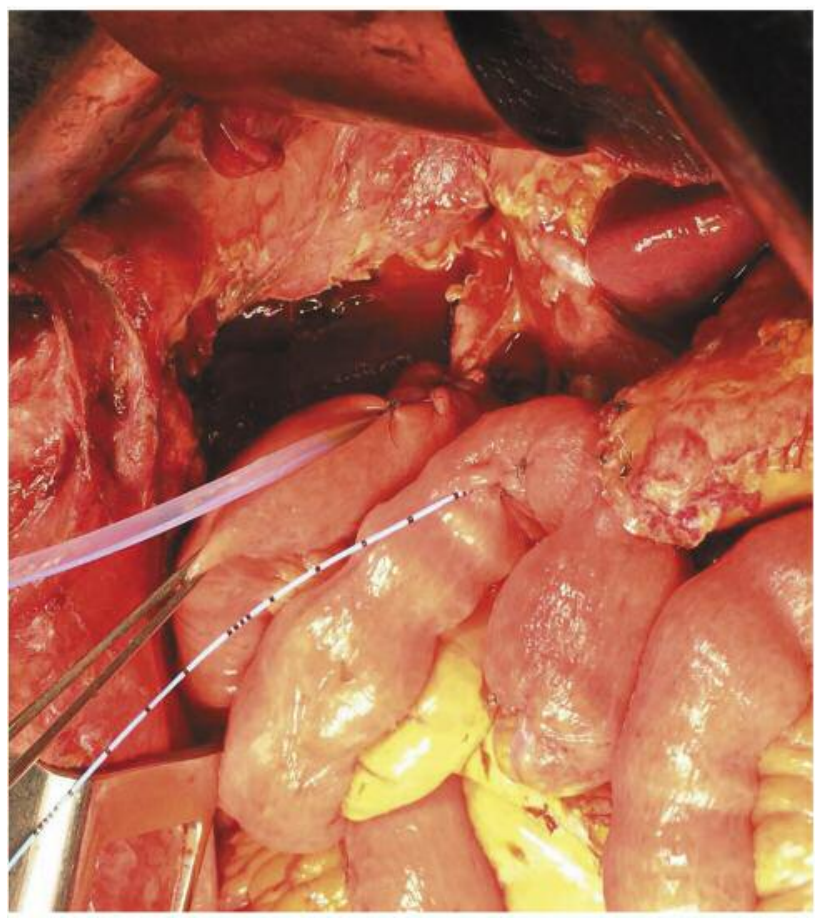

Figure 8. Biliary and pancreatico-jejunal anastomosis were protected by stent placement. 
synchronous colonic lesions (12). The rationale for this aggressive surgical approach consisting of multiple visceral resections has been widely demonstrated by those who studied the benefits of debulking surgery for advanced-stage colonic cancer (18). The propensity of colonic cancer to spread via peritoneal and lymphatic route, inducing in this way peritoneal carcinomatosis and lymph node metastases without parenchymatous lesions with hematogenous origin, enabled consideration of debulking surgery in these cases $(19,20)$. The benefits reported so far in patients with advanced-stage or relapsed ovarian cancer presenting disseminated lesions, as well as the progress reported in hepatobiliopancreatic surgery, encouraged surgeons worldwide to perform pancreatic, splenic, gastroduodenal and hepatic resections as part of debulking surgery for advanced-stage disease, with acceptable rates of postoperative complications (18-27). The acceptable rates of postoperative morbidity, as well as the long-term survival rates, demonstrated the efficacy of these procedures, which for a long time had been considered not to be appropriate, and even contraindicated if upper abdominal involvement was present $(28,29)$.

When it comes to the impact of synchronous colonic lesions on survival, different opinions have been expressed; while one of the first authors who studied the impact of synchronous lesions on survival demonstrated a poorer prognostic of these cases when compared to those who had been diagnosed with solitary lesions (15), more recent studies demonstrated similar survival rates; moreover, other prognostic factors, such as histopathological subtype and association of genetic mutations, should be taken into consideration in order to predict survival $(12,30)$.

The other particularity of our case was the association of a complex gastrocolic-cutaneous fistula at the time of presentation. Usually seen during the postoperative or postprocedural periods, complex digestive tract fistulas also occur in patients with inflammatory bowel disease or advanced neoplastic processes (8-11, 31-34). In the study conducted by Gluszek et al. and published in 2011, 32 patients with digestive tract fistulas were included; among these cases, association of a neoplastic process was seen in four and consisted of bronchoesophageal fistula due to pulmonary or esophageal carcinoma in three cases and an enterovaginal fistula due to an anal carcinoma in one case. In all four cases, conservative management was attempted, consisting of antibiotic treatment, parenteral nutrition, analgesic drugs, proton pump inhibitors and gastrostomy tube placement (in one case), followed by palliative care. In other seven cases, intestinal fistulas were reported and were surgically managed in most cases; however, in all these cases the underlying process which induced the development of fistula consisted of inflammatory bowel disease and not a neoplastic process, all patients having a good postoperative outcome (34).
Initially, before the 1930s, patients presenting with gastrocolic fistulas were routinely submitted to excision of the fistulous tract en bloc with the involved gastric and colonic segment, while the continuity of the digestive tract was reestablished by a Billroth I or Billroth II anastomosis and a side-to-side colo-colonic anastomosis. However, at that time, most cases developed severe postoperative complications (35, 36). Due to this fact, one decade later, Pfeiffer proposed preliminary colostomy prior to resection, with better outcomes (37). However, in more recent decades, such multiple visceral resections have been performed with better results in terms of early postoperative outcomes and long-term survival, especially in cases in which adjuvant chemotherapy is administered $(7,38,39)$. Forshaw et al. reported the case of a 24-year-old patient who was diagnosed with a gastrocolic fistula associated with a transverse colonic tumor; the patient was successfully submitted to radical, en bloc resection consisting of a subtotal gastrectomy, transverse colectomy and small bowel resection, followed by six cycles of 5-fluorouracil and folinic acid, and was alive with no signs of recurrent disease at 10-year follow-up (7). A similar case was reported by Matsuo et al.; a 72-year-old patient was diagnosed with a transverse colonic tumor with gastrocolic fistula and was submitted to a two-thirds distal gastrectomy and right colectomy; the authors reviewed the results of 14 similar cases which had been reported until then in the Japanese literature and underlined that although resection was possible in nine cases, long-term survival was reported for only one case (39).

When it comes to local invasion and the association of a complex gastrocolic-cutaneous fistula, these two aspects represent another particularity of our case. The long period of evolution of the malignant process, as well as the associated peritumoral inflammatory processes, might explain the development of a complex gastrocolic-cutaneous fistula. The long evolution of the neoplasia might also explain the necessity for performing such an extensive procedure also involving a pancreatoduodenectomy. Complex fistula itself usually requires subtotal gastrectomy and transverse colonic resection; however, the deep infiltration of the duodenal wall and of the pancreatic head in our case also necessitated cephalic pancreatoduodenectomy, significantly increasing the risk of postoperative complications. Although during the postoperative period the patient had a difficult evolution in the first week, due to the development of a febrile syndrome of unknown origin, the final postoperative course was uneventful, the patient being discharged on the 16th postoperative day.

\section{Conclusion}

Synchronous colonic adenocarcinoma and complex gastrocolic-cutaneous fistulas due to transverse colonic cancer represent two atypical situations that were revealed in the same patient in our case. Although an aggressive 
surgical approach was followed, the overall postoperative evolution of the patient was a favorable one, with no signs of recurrent disease or distant metastases being reported at 1-year follow-up. In conclusion, the presence of such a complex situation should not preclude performing a complete cytoreduction, while good results still being possible.

\section{Acknowledgements}

This work was supported by a grant of the Romanian National Authority for Scientific Research and Innovation, CNCS UEFISCDI, project number PN-II-RU-TE-2014-4-2533.

\section{References}

1 Cunliffe WJ, Hasleton PS, Tweedle DE and Schofield PF: Incidence of synchronous and metachronous colorectal carcinoma. Br J Surg 71: 941-943, 1984.

2 Polk HC Jr., Spratt JS Jr. and Butcher HR Jr.: Frequency of multiple primary malignant neoplasms associated with colorectal carcinoma. Am J Surg 109: 71-75, 1965.

3 Papadopoulos V, Michalopoulos A, Basdanis G, Papapolychroniadis K, Paramythiotis D, Fotiadis P, Berovalis P and Harlaftis N: Synchronous and metachronous colorectal carcinoma. Tech Coloproctol 8(Suppl 1): s97-s100, 2004.

4 Tziris N, Dokmetzioglou J, Giannoulis K, Kesisoglou I, Sapalidis K, Kotidis E and Gambros O: Synchronous and metachronous adenocarcinomas of the large intestine. Hippokratia 12: 150-152, 2008.

5 Greenstein AJ, Slater G, Heimann TM, Sachar DB and Aufses AH Jr.: A comparison of multiple synchronous colorectal cancer in ulcerative colitis, familial polyposis coli, and de novo cancer. Ann Surg 203: 123-128, 1986.

6 Ikeda Y, Saku M, Kawanaka H, Muranaka T, Takeshita M, Watanabe J, Yoshida K and Sugimachi K: Distribution of synchronous and metachronous multiple colorectal cancers. Hepatogastroenterology 51: 443-446, 2004.

7 Forshaw MJ, Dastur JK, Murali K and Parker MC: Long-term survival from gastrocolic fistula secondary to adenocarcinoma of the transverse colon. World J Surg Oncol 3: 9, 2005.

8 Abeygunasekera S, Freiman J, Engelman J, Glenn D and Craig P: Gastropancreaticocolic fistula: complication of a benign ulcer. Gastrointest Endosc 59: 450-452, 2004.

9 Ruffolo C, Angriman I, Scarpa M, D'Odorico A, Polese L, Barollo M, Bertin M, Pagano D and D'Amico DF: A gastrocolic fistula in Crohn's disease. Dig Dis Sci 50: 933-934, 2005.

10 Haller A: Opuscula pathologica, 1755. In: Die klinische und radiologische diagnose der fistula gastrocolica. Voorheeve $\mathrm{N}$ (ed.). Deutsch Arch Klein Med Vol. 106, p. 294-308, 1912.

11 Stamatakos M, Karaiskos I, Pateras I, Alexiou I, Stefanaki C and Kontzoglou K: Gastrocolic fistulae; From Haller till nowadays. Int J Surg 10: 129-133, 2012.

12 Lam AK, Chan SS and Leung M: Synchronous colorectal cancer: clinical, pathological and molecular implications. World J Gastroenterol 20: 6815-6820, 2014.

13 Latournerie M, Jooste V, Cottet V, Lepage C, Faivre J and Bouvier AM: Epidemiology and prognosis of synchronous colorectal cancers. Br J Surg 95: 1528-1533, 2008.
14 Kiran RP, Khoury W, Church JM, Lavery IC, Fazio VW and Remzi FH: Colorectal cancer complicating inflammatory bowel disease: similarities and differences between Crohn's and ulcerative colitis based on three decades of experience. Ann Surg 252: 330-335, 2010.

15 Lam AK, Carmichael R, Gertraud BP, Gopalan V, Ho YH and Siu S: Clinicopathological significance of synchronous carcinoma in colorectal cancer. Am J Surg 202: 39-44, 2011.

16 Mohammadi M, Kristensen MH, Nielsen HJ, Bonde JH and Holck S: Qualities of sessile serrated adenoma/polyp/lesion and its borderline variant in the context of synchronous colorectal carcinoma. J Clin Pathol 65: 924-927, 2012.

$17 \mathrm{Eu} \mathrm{KW,} \mathrm{Seow-Choen} \mathrm{F} \mathrm{and} \mathrm{Goh} \mathrm{HS:} \mathrm{Synchronous} \mathrm{colorectal} \mathrm{cancer}$ in an Oriental population. Int J Colorectal Dis 8: 193-196, 1993.

18 Sugarbaker PH: Surgical management of carcinomatosis from colorectal cancer. Clin Colon Rectal Surg 18: 190-203, 2005

19 Sadeghi B, Arvieux C, Glehen O, Beaujard AC, Rivoire M, Baulieux J, Fontaumard E, Brachet A, Caillot JL, Faure JL, Porcheron J, Peix JL, Francois Y, Vignal $J$ and Gilly FN: Peritoneal carcinomatosis from non-gynecologic malignancies: results of the EVOCAPE 1 multicentric prospective study. Cancer 88: 358-363, 2000.

20 Jayne DG, Fook S, Loi C and Seow-Choen F: Peritoneal carcinomatosis from colorectal cancer. Br J Surg 89: 1545-1550, 2002.

21 Bacalbasa N, Balescu I, Dima S, Brasoveanu V and Popescu I: Pancreatic resection as part of cytoreductive surgery in advanced-stage and recurrent epithelial ovarian cancer-a singlecenter experience. Anticancer Res 35: 4125-4129, 2015.

22 Bacalbasa N, Dima S, Balescu I, David L, Brasoveanu V and Popescu I: Results of primary cytoreductive surgery in advanced-stage epithelial ovarian cancer: a single-center experience. Anticancer Res 35: 4099-4104, 2015.

23 Bacalbasa N, Balescu I, Dima S, Brasoveanu V and Popescu I: Hematogenous splenic metastases as an independent negative prognosis factor at the moment of primary cytoreduction in advanced stage epithelial ovarian cancer--a single center experience. Anticancer Res 35: 5649-5654, 2015.

24 Bacalbasa N, Dima S, Brasoveanu V, David L, Balescu I, Purnichescu-Purtan R and Popescu I: Liver resection for ovarian cancer liver metastases as part of cytoreductive surgery is safe and may bring survival benefit. World J Surg Oncol 13: 235, 2015.

25 Bacalbasa N, Balescu I, Dima S and Popescu I: Long-term survivors after liver resection for ovarian cancer liver metastases. Anticancer Res 35: 6919-6923, 2015.

26 Mirancea GV, Morosanu AM, Carniciu S, Dima S, Bacalbasa N, Popescu I, Ionescu-Tirgoviste C and Mirancea N: Relevant infrastructural alterations in a pancreatic neuroendocrine tumor: an insulinoma case. Rom J Morphol Embryol 55: 659-668, 2014.

27 Brasoveanu V, Anghel C, Barbu I, Pautov M, Ionescu MI, Motthor M, Balescu I, Dima $S$ and Bacalbasa N: Pancreatoduodenectomy en bloc with portal and superior mesenteric artery resection-a case report and literature review. Anticancer Res 35: 1613-1618, 2015.

28 Eisenhauer EL, Abu-Rustum NR, Sonoda Y, Levine DA, Poynor EA, Aghajanian C, Jarnagin WR, DeMatteo RP, D'Angelica MI, Barakat RR and Chi DS: The addition of extensive upper abdominal surgery to achieve optimal cytoreduction improves survival in patients with stages IIIC-IV epithelial ovarian cancer. Gynecol Oncol 103: 1083-1090, 2006. 
29 Eisenkop SM, Spirtos NM, Friedman RL, Lin WC, Pisani AL and Perticucci S: Relative influences of tumor volume before surgery and the cytoreductive outcome on survival for patients with advanced ovarian cancer: a prospective study. Gynecol Oncol 90: 390-396, 2003.

30 Nosho K, Kure S, Irahara N, Shima K, Baba Y, Spiegelman D, Meyerhardt JA, Giovannucci EL, Fuchs CS and Ogino S: A prospective cohort study shows unique epigenetic, genetic, and prognostic features of synchronous colorectal cancers. Gastroenterology 137: 1609-1620, 2009.

31 Torres-Garcia AJ, Arguello JM and Balibrea JL: Gastrointestinal fistulas: pathology and prognosis. Scand J Gastroenterol Suppl 207: 39-41, 1994.

32 Singh V and Wadleigh R: Gastrocolic fistula as a complication of colon carcinoma - a case report. Acta Oncol 36: 817-818, 1997.

33 Saint-Marc O, Tiret E, Vaillant JC, Frileux P and Parc R: Surgical management of internal fistulas in Crohn's disease. J Am Coll Surg 183: 97-100, 1996.

34 Gluszek S, Korczak M, Kot M, Matykiewicz J and Koziel D: Digestive system fistula: a problem still relevant today. Pol Przegl Chir 83: 32-41, 2011
35 Marshall SF and Knud-Hansen J: Gastrojejunocolic and gastrocolic fistulas. Ann Surg 145: 770-782, 1957.

36 Hansen CP, Christensen A, Thagaard CS and Lanng C: Gastrocolic fistula resulting from chronic pancreatitis. South Med J 82: 1309-1310, 1989.

37 Pfeiffer DB: The value of preliminary colostomy in the correction of gastrojejunocolic fistula. Ann Surg 110: 659-668, 1939.

38 Aydin U, Yazici P, Ozutemiz O and Guler A: Outcomes in the management of gastrocolic fistulas: a single surgical unit's experience. Turk J Gastroenterol 19: 152-157, 2008.

39 Matsuo S, Eto T, Ohara O, Miyazaki J, Tsunoda $\mathrm{T}$ and Kanematsu T: Gastrocolic fistula originating from transverse colon cancer: report of a case and review of the Japanese literature. Surg Today 24: 1085-1089, 1994.

Received March 5, 2017

Revised March 25, 2017

Accepted March 31, 2017 